\title{
Paraíba em armas: João da Maia da Gama e a Guerra dos Mascates*
}

\author{
Armed Paraíba: João da Maia da Gama and the Mascate War
}

\section{Isabela Augusta Carneiro Bezerra"*}

Resumo: Após prestar anos de serviços militares na Índia e na Guerra da Sucessão Espanhola (I702-I7I4), o lusitano João da Maia da Gama foi agraciado com o cargo de capitãomor e governador da Paraíba em I708. Aportando na capitania em um crítico período da história colonial brasileira, João da Maia participou ativamente da administração colonial, traçando planos e estratégias nos campos político, econômico e militar, inclusive, envolvendo-se na Guerra dos Mascates (I7IO-I) em Pernambuco. O presente artigo pretende analisar como se efetivou a sua intervenção no conflito pernambucano - ação mais lembrada pela historiografia -, buscando perceber quais as possíveis motivações e estratégias políticas envolvidas na ação do governador, bem como observar suas práticas no exercício de suas funções governamentais, observando seus limites jurisdicionais e a possibilidade de autonomia frente às diretrizes metropolitanas.

Palavras-chave: Capitania da Paraíba. Guerra dos Mascates. João da Maia da Gama.

Abstract: After rendering military services by years in India and in The War of the Spanish Succession (1702-I714), the Lusitanian João da Maia da Gama was awarded with the charge of captain-major and governor of Paraiba in 1708. Coming into port at the captainship in a critical period of Brazilian colonial history, João da Maia took part actively in the colonial administration, outlining plans and strategies in the military, economic and political fields, including an involvement in The Mascate War (I7IO-I7II) in Pernambuco The present article intends to analyse how his intervention in Pernambuco's conflict was put into effect - the most remembered action by historiography -, seeking to perceive the plausible political motivations and strategies involved in the governor's action, as well as observe their juridic boundaries and the possibility of autonomy in face to the metropolitan guidelines.

\footnotetext{
* Este artigo é parte da pesquisa realizada para a dissertação intitulada A serviço d'el-Rey: o governo de João da Maia da Gama na Capitania da Paraíba (I708 - I7I7), defendida no Programa de Pós-Graduação em História da Universidade Federal da Paraíba em 2015.

* Professora do Instituto Federal de Educação, Ciência e Tecnologia da Paraíba. Licenciada e Mestra em História pela Universidade Federal da Paraíba. Doutoranda em História Moderna pela Universidade de Coimbra.
} 


\section{C) Gitiston'RICA}

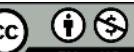

Keywords: Captainship of Paraíba. The Mascate War. João da Maia da Gama.

Não tenho carne, nem sangue, nem amigo, nem parente, nem cousa do mundo, que me obrigue a fazer o que faço, mais que o serviço de Deos, e d' El-Rey.

João da Maia da Gama

Ano de I708. O lusitano João da Maia da Gama atingia as terras paraibanas a fim de exercer as funções para as quais havia sido designado pela realeza portuguesa: ser capitãomor e governador da capitania da Paraíba, cargo que exerceria por três longos triênios. Os serviços militares empreendidos nos vários domínios do império português o habilitaram a ser agraciado com o governo da Paraíba, inaugurando em sua carreira uma dimensão inédita no âmbito da sua prestação de serviços à Coroa portuguesa. Depois de quinze anos mergulhado em jornadas militares ${ }^{\mathrm{I}}$, passaria a desempenhar funções administrativas como governador da Paraíba, durante os anos de I708 a I7I7.

Nesse período, a capitania enfrentava, no âmbito militar, um cenário delicado. Viviase um período de grave ameaça externa devido ao envolvimento de Portugal na Guerra de Sucessão Espanhola (1702-I714), fator que tornara suas colônias vulneráveis a ataques inimigos, em especial, a investidas francesas ${ }^{2}$. No período de I7OI a I7II, os governadores da Paraíba, como os de outras capitanias, foram continuamente alertados pelas autoridades portuguesas sobre o risco de uma iminente incursão francesa em seus territórios ${ }^{3}$. As invasões, de fato, acabariam incidindo no Rio de Janeiro em I7Io e I7II.

Paralelamente, no plano interno, a situação também era preocupante. Não à toa, Laura de Mello e Souza classificou o início do século XVIII como um dos períodos "mais conturbados da história do domínio português na América, aberto com a Guerra dos

\footnotetext{
${ }^{\text {I }}$ Antes de assumir o governo da capitania, João da Maia prestou serviços militares na Índia, na África e na Guerra da Sucessão Espanhola (I702-I7I4). Após o término de sua gestão na Paraíba, foi nomeado como governador e capitão-general do Estado do Maranhão em 1722, cargo que ocuparia até I728, quando então regressou definitivamente ao reino (MARTINS, I944, v. I, p. 43-59).

${ }^{2}$ A participação portuguesa no conflito provocou desdobramentos nos seus domínios ultramarinos. Como elenca Boxer, várias possessões ao redor do império português foram atacadas pelo inimigo franco-espanhol, em especial, o Brasil, sendo a cidade do Rio de Janeiro a mais cobiçada, em função do escoamento do ouro de Minas Gerais, através de seu porto (BOXER, 2000, p. II3).

${ }^{3}$ Carta para o Capitão-mor da Paraiba Francisco de Abreu Pereira I6/I2/I70I, DHBN, vol. XXXIX, p. 154-5; Carta para o Capitão-mor da Paraiba Francisco de Abreu Pereira 5/2/1702, DHBN, vol. XXXIX, p. 158; Requerimento (cópia) do capitão-mor da Paraíba, João da Maia da Gama, ao rei [D. João V] I7I2, AHU_ACL_CU_oI4, Cx. 4, D. 335; Carta para o Capitão-mor da Paraiba João da Maia da Gama 19/9/1710, DHBN, vol. XXXIX, p. 250; Carta que escreveu ao Capitão-mor da Paraíba, João da Maia da Gama 9/8/I7II, DHBN, vol. XXXIX, p. 292; MACHADO, I977, p. 34I.
} 


\section{C) GitsentórICA}

Emboabas, em Minas (I707-I709) e marcado, no final, pela Revolta do Terço Velho, em Salvador (1728)" (SOUZA, 20II, p. 56).

Nesse interregno, está compreendida uma das mais notáveis revoltas coloniais, a Guerra dos Mascates (I7IO-I7II). Conflito opondo senhores de engenho de Olinda a negociantes recifenses - a maior parte desses imigrantes oriundos de Portugal -, quando da elevação de Recife, estabelecida por decreto régio, à condição de vila autônoma. Com a eclosão da sedição, João da Maia tomou partido, dando amplo apoio aos recifenses.

A intervenção de João da Maia da Gama no conflito em Pernambuco é a sua ação mais lembrada pela historiografia. O envolvimento do governador da Paraíba foi de tal dimensão que até mesmo chegou a ser taxado como cabeça do levante pelo governador-geral D. Lourenço de Almada4 ${ }^{4}$ Em virtude de sua adesão aos mascates, pairava na capitania o receio de uma insurreição da nobreza paraibana - parente e aliada da nobreza pernambucana - e mesmo de uma invasão dos nobres vizinhos, em retaliação à ingerência do governador.

Diante desse quadro, João da Maia efetivou várias medidas no âmbito militar. A preocupação com a defesa do território expressa em sua gestão era, antes de tudo, uma atribuição inerente ao cargo de capitão-mor, comandante supremo das forças militares na capitania. Segundo estabelecia os regimentos, era sua obrigação responsabilizar-se pela segurança do território frente às possíveis invasões aos domínios portugueses (PRADO JR., 2000, p. 315; RICUPERO, 2009, p. 136; SALGADO, I985, p. 243-4).

No entanto, as medidas, além de compreenderem um encargo próprio do seu posto, estavam relacionadas às temidas invasões e sublevações, sendo o alastramento das alterações de Pernambuco para o território paraibano a mais concreta das ameaças.

\section{Capitania com armas na mão pronta para a resistência}

Desde que recebeu a notícia, no dia I9 de outubro de I7IO, que "se tinha atirado traidora e aleivosamente" no governador de Pernambuco Sebastião de Castro e Caldas5 , João da Maia da Gama procurou intermediar a negociação entre os grupos rivais. Conforme bem elucida Mello (2003, p. 303), o governador procurou desempenhar papel de primeiro plano

\footnotetext{
${ }^{4}$ Carta que escreveu ao Capitão-mor da Paraíba, João da Maia da Gama 9/8/I7II, DHBN, vol. XXXIX, p. 29I-2

5 Carta do [capitão-mor da Paraíba], João da Maia da Gama, ao rei [D. João V] I6/ı2/I7Io, AHU_ACL_CU_oI4, Cx. 4, D. 324 .
} 


\section{C) Gitistór RICA}

nas alterações pernambucanas. De fato, ele desejava colocar-se como mediador e pacificador do combate.

Oferecendo imediato auxílio a Castro e Caldas e anunciando estar "prompto $\mathrm{p}^{\mathrm{a}}$ lhe hir assestir, $\mathrm{p}^{\mathrm{a}} \mathrm{o}$ hir deffender com todo o poder desta Capnia e ajudallo a castigar tão temeraria rezolução", João da Maia recebeu como resposta o aflito apelo por socorro de gente e mantimentos, entoado pelo acuado governador de Pernambuco ${ }^{6}$

A partir disso, João da Maia decidiu ir socorrer a capitania vizinha pessoalmente, empreendendo viagem até a região conflagrada. Ao governador pernambucano, insistiria para que desistisse das prisões efetuadas após o atentado, enquanto aos olindenses, lembrarlhes-ia da fidelidade e respeito que deviam ao monarca e aos seus ministros. Recorreria ainda à história, recordando à nobreza que seu mau procedimento não se coadunava com as heroicas ações protagonizadas por seus pais, quando da restauração pernambucana ${ }^{7}$.

No entanto, próximo a Goiana, João da Maia desistiu de prosseguir na jornada. Acontece que o governador foi informado da aparição de navios supostamente inimigos na costa pernambucana ${ }^{8}$. Além disso, a comitiva cruzou com o emissário do ouvidor de Pernambuco, Luís de Valençuela Ortiz, o qual assegurava estar controlada a situação em Recife, motivos alegados pelo governador paraibano para regressar a Paraíba ${ }^{9}$. Embora não declarado, certamente também coexistia o receio de a sua própria capitania levantar-se atrás dele, repetindo assim a sedição da nobreza em terras paraibanas (BOXER, 200o, p. I42). Segundo Manuel dos Santos, autor de Narração histórica das calamidades de Pernambuco ${ }^{I O}$, o governador da Paraíba

Por duas ou trez vezes intentara vir pessoalmente socorrel-a [Recife], porém por lhe advertirem, que, si tal fizesse, os Parahibanos na sua auzencia farião o que na sua prezenla não ouzavão, especialmente os devotos da faç̧ão da nobreza, que erão muitos, por esta cauza o não chegou a executar (SANTOS, I890, p. 227).

\footnotetext{
${ }^{6}$ Carta do [capitão-mor da Paraíba], João da Maia da Gama, ao rei [D. João V] I6/12/1710, AHU_ACL_CU_oI4, Cx. 4, D. 324.

7 Idem.

${ }^{8}$ João da Maia não fornece mais informações sobre os navios, mas, provavelmente, temia um ataque francês na capitania.

${ }_{9}^{9}$ Carta do [capitão-mor da Paraíba], João da Maia da Gama, ao rei [D. João V] I6/12/1710, AHU_ACL_CU_oI4, Cx. 4, D. 324.

Io Escrita em sua forma final em 1749 e publicada na Revista do Instituto Histórico e Geográfico Brasileiro em I890 (BOXER, op. cit., p. I49).
} 


\section{C) Gitistór RICA}

Com a fuga, no dia 7 de novembro de $\mathrm{I} 7 \mathrm{IO}$, de Castro e Caldas para a Bahia ${ }^{\mathrm{II}}$, o bispo D. Manuel foi convocado para assumir o governo de Pernambuco ${ }^{12}$. O prelado viajava junto a João da Maia, pois se encontrava em visita a Paraíba, quando da eclosão do conflito.

Abandonando a empreitada, João da Maia resolveu então enviar algumas autoridades para acompanhar o bispo. A comitiva, composta pelos desembargadores Cristóvão Soares Reimão e Manoel Velho de Miranda, o ex-ouvidor de Pernambuco José Inácio Arouche e o ouvidor da Paraíba Jerônimo Correia do Amaral, deveria auxiliar na transição do governo, desempenhando o papel que ele estava disposto a cumprir.

Em junho do ano seguinte, quando a cidade de Recife é sitiada pelas milícias rurais bloqueio que duraria um pouco mais de três meses -, João da Maia trocou vasta correspondência com os pernambucanos. Escreveu carta à Câmara de Olinda, em que se oferecia para servir de mediador na contenda. Irritados com o procedimento do governador paraibano na disputa, os camarários rechaçaram sua proposta e reprovaram sua conduta duramente. Questionaram a jurisdição do governador, cuja extensão não abarcava o território pernambucano. Para a Câmara, João da Maia agia como se fosse um "Capitão Geral deste Estado" ou um governador-geral do Brasil, "usurpando a sua jurisdição, promettendo perdões em nome de El-Rei, como se tivera poderes para isso". Protestaram os camarários:

\footnotetext{
Vmc., não sendo nosso Capitão General, nem tendo dominio algum sobre nós, escreveu a este Senado, ameaçando e mandado, e se assignou na forma em que fazem os superiores para com os subditos. E supposto que algumas vezes nos falla pedindo, comtudo não nos obriga quando pede, porque nos offende quando manda, e ameaça; e não he este o estylo de quem não tem mais jurisdição, que a que El-Rei nosso Senhor lhe determinou. (...) Não nos consta que tenha Vmc. ordem de El-Rei mais que para governar a Provincia, e assim se não póde intrometter na jurisdição alheia. (GAMA ${ }^{13}$, 1977, p. 78-9)
}

\footnotetext{
II Castro e Caldas fugiu na madrugada do dia 7 de novembro, após uma tentativa fracassada de negociação com os revoltosos. O governador propôs o fim de levante em troca da libertação dos autores do atentado. Todavia, a oferta foi descartada, pois os partidários de Olinda não se contentavam com a liberdade dos sediciosos e exigiam também a prisão de Castro e Caldas e dos principais mascates (MELLO, op. cit., p 295-6).

I2 Uma carta régia de 8 de abril de 1707 previa que, em caso de vacância, deveria assumir o posto de governador o mestre-de-campo do terço de Olinda, João de Freitas da Cunha e, na impossibilidade deste, o bispo de Olinda. Como o primeiro havia falecido, convocou-se com urgência D. Manuel (Ibidem, p. 297).

${ }_{13}$ Ao ocupar-se da Guerra dos Mascates, a obra de Fernandes Gama Memórias históricas da província de Pernambuco baseia-se quase inteiramente no relato feito pelo padre Antonio Gonsalves Leitão, contemporâneo das alterações em Pernambuco (GAMA, 1977, p. 54).
} 


\section{C) GitistóróRICA}

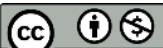

Cientes de toda a ajuda prometida pelo governador de gente e mantimentos aos partidários dos mascates, os camarários acusaram João da Maia de ser a causa de "toda a ruína de Pernambuco, desserviço de Sua Magestade, prejuízo de Sua Real Fazenda, e a destruição de seus Vassallos". Por esse motivo, queixaram-se ao monarca e ao governadorgeral do Brasil das atitudes do capitão-mor da Paraíba (Ibidem, p. 79 e 85).

João da Maia também escreveu às Câmaras de Itamaracá e Igarassu requerendo que não se alterassem contra os moradores de Recife. Outras cartas do governador paraibano endereçadas ao Recife foram interceptadas pelo partido olindense. Encontradas ocultas no forro do chapéu de um negro emissário do governador, destinavam-se aos capitães de algumas freguesias pernambucanas, ao padre João da Costa da congregação do Oratório, um dos inimigos da nobreza e mentores da sublevação, e ao chefe militar João da Mota, líder da rebelião (Ibidem, 8I-2; SANTOS, op. cit., p. I2I).

De acordo com Gama (op. cit., p. 77), a carta para o padre João da Costa comunicavalhe minuciosamente o que havia escrito à Câmara de Olinda e aconselhava-o do modo como deveriam os levantados pedir-lhe socorro, “a fim d'elle ter pretexto de marchar, para o que já se achava com tres mil homens, inclusive muitos Tapuias”. Já a correspondência para João da Mota, segundo Maximiamo Machado, informava-o "da resolução em que estava de concitar o povo de Goiana contra o governo do bispo, e reunindo-se depois com as tropas da Parahyba atacar a linha de cerco pela retaguarda e acabar por uma vez com os enfados da nobreza da terra" (MACHADO, op. cit., p. 369).

João da Maia também se correspondeu com D. Manuel, culpando-o pela guerra, em virtude da sua demissão do governo militar. Acontece que a 28 de junho de I7II, em consideração ao seu estado sacerdotal, o bispo resolveu demitir-se do poder temporal, delegando o governo militar a uma junta pró-olindense composta por Valençuela Ortiz, pelo mestre-de-campo do terço de Olinda, Cristóvão de Mendonça Arrais, e pelos oficiais da Câmara, e nomeando João de Barros Rego como comandante do exército (MELLO, op. cit., p. 383).

A ação foi duramente criticada pelo governador paraibano ${ }^{14}$. Segundo alegava João da Maia, embora o bispo sustentasse que demitira de si o governo por não lhe ser permitido, como eclesiástico, fazer guerra, na verdade, tal demissão e delegação de poderes a "intrusos" ou "supostos governadores", seriam manobras engendradas justamente no intuito evidente

\footnotetext{
I4 O governador-geral D. Lourenço de Almada também estranhou a atitude de D. Manuel de demitir-se do governo militar quando, na verdade, devia preservar integralmente a jurisdição delegada pelo rei e recomendou que restabelecesse seus poderes (MELLO, op. cit., p. 386).
} 


\section{C) Gitcostórica}

de manter a guerra, uma vez que entregava o governo a inimigos recifenses, fomentadores do conflito. Além disso, ao desmembrar os poderes de governador providos pelo monarca, o prelado atropelava a lei do costume, excedendo sua jurisdição como se absolutamente fosse o rei e senhor dela'5.

Sem a demissão do governo, João da Maia assegurava que não haveria cerco ao Recife. Ao contrário, "se o Sr. Bispo se não retirára, estivera tudo acabado, e quieto" (GAMA, op. cit., p. I05). O governador da Paraíba acusava explicitamente D. Manuel de fomentar a guerra contra os moradores do Recife:

He V. Illma o que faz a dita guerra, e com muito socego esta ouvindo laborar de Artilharia, a se perguntar (supponho deligencia desnecessária, por V. Ilmª o saber muy bem) se os tiros fazem effeyto, ouviria que lá matarão a fulano, e a outros muytos, a outros quebrarão as pernas, e que nada haveria se V. Illma não demitira de sy o governo, antes com o poder do cargo de Governador fulminara graves penas, e os fizera executar n'aquelles que sahissem das suas cazas, e não consentira que os aggregassem e violentassem para fazer huma guerra injusta ao Recife. ${ }^{16}$

João da Maia solicitou que D. Manuel usasse seu poder de governador e de prelado para promover a retirada de todos os sitiantes, levantando assim o cerco e permitindo a entrada de víveres no Recife. Solicitou também licença para ir socorrer a praça a fim de promover a quietação de $\operatorname{todos}^{17}$. O bispo jamais chegou a responder à carta. Nessa altura, a relação entre o governador paraibano e o prelado de Pernambuco havia azedado. Em lados opostos, cada um já tinha demarcado claramente sua posição no conflito.

Além de tentar dissuadir D. Manoel do sítio ao Recife, João da Maia também lançou um manifesto à nobreza de Pernambuco, em I8 de julho de I7II, a fim de demovê-la da guerra. Além de reiterar a argumentação exposta ao bispo, alertava que os revoltosos incorriam no crime de lesa-majestade, por não possuírem expresso mandado do rei. Afirmava que, caso desistissem das armas, os sitiantes poderiam contar com a certeza do perdão régio, oferecendo-se ele mesmo a solicitá-lo (Ibidem, p. 133-5).

Ao longo do conflito, João da Maia procurou, ao menos em seu discurso, colocar-se em uma posição de neutralidade. No próprio manifesto à nobreza, destacou que não era

\footnotetext{
${ }^{15}$ Carta dos oficiais da Câmara da Paraíba, ao rei [D. José I], I9/5/I756, AHU_ACL_CU_OI4, Cx. I9, D. I495;

${ }^{16}$ Idem.

${ }^{17}$ Idem.
} 


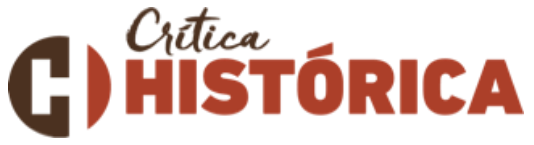

"cumplice, nem interessado por uma nem por outra parte" (SANTOS, op. cit., p. 136). Segundo declarou, toda sua diligência era justificada apenas pela sua lealdade a Deus e a ElRey. E é justamente em prol do serviço de Deus e D' el-Rey que ele, encerrando o manifesto, solicitou o final do cerco ao Recife:

\begin{abstract}
E assim espero, que os mais dezapaixonados, mais livres, e mais izentos, ponderados os solidos fundamentos e razões d' este papel, os obriguem com rogos, com a amizade e com os vinculos do sangue, a se reduzirem á paz e quietação ; e do contrario se segue a perdição do Recife, a perdição da cidade e de todos geralmente : e a grandes e pequenos protesto pelas taes destruições, ruinas, e consequencia ; e para justificar a todos o meo zelo, e a Sua Magestade a minha lealdade, e a Deos a minha deligencia, sem temor, nem dos homens nem da morte, com os olhos só no serviço de Deos e de elrei, fiz este papel, e o faço publico a todos. (Idem)
\end{abstract}

Paralelamente às tentativas de negociação, João da Maia atuou oferecendo apoio logístico e militar aos mascates. O governador confessou ter embarcado I85 alqueires de farinha e sete pipas de carne ao Recife (GAMA, op. cit., p. I08). Os mantimentos agenciados na Paraíba tiveram fundamental importância para a resistência dos mascates. Assinala Mello que a reserva de víveres acumulada pelos mascates era insuficiente para os três imprevistos meses de sítio. De acordo com autor, "os estoques reunidos quando da preparação do levante se esgotaram e a situação de penúria só foi atenuada por suprimentos vindos da Paraíba e de portos do litoral" (MELLO, op. cit., p. 388).

João da Maia, inclusive, adotou medidas em relação ao conflito na sua própria capitania. Acontece que os desdobramentos pernambucanos também se fizeram sentir na Paraíba. De acordo com o governador, além de pretenderem apoderar-se da praça de Recife, a nobreza pernambucana também desejava assenhorear-se da capitania da Paraíba e apossar-se da fortaleza de Cabedelo. Para concretizar tal intento, havia reunido gente no Caricé de Goiana para invadirem a Paraíba. Ao descobrir a conspiração da nobreza para sublevar a Paraíba, João da Maia, a pretexto de defender a capitania de um ataque francês, relatou que tratou de proteger, no fim de janeiro de I7II, a fortaleza de Cabedelo, onde estocou mantimentos e pôs uma boiada, comprados ambos às suas custas ${ }^{18}$.

I8 Requerimento (cópia) do capitão-mor da Paraíba, João da Maia da Gama, ao rei [D. João V] I7ı2, AHU_ACL_CU_ol4, Cx. 4, D. 335. 


\section{C) Gitistór RICA}

Ainda segundo o relato de João da Maia, ele se pôs em armas e tocando a rebate juntou mais de 2 mil homens ${ }^{19}$ na cidade da Paraíba "capaz de rebater e castigar os levantados", pondo "toda a sua capitania com armas na mão prompta $\mathrm{p}^{\mathrm{a}}$ a rezistência". Por se tratarem de pessoas muito pobres, o governador teria lhes assistido, a partir da sua própria fazenda, com carnes e farinhas, permanecendo com esta despesa de 2 de janeiro até IO ou I5 de fevereiro de $\mathrm{I}_{7 \mathrm{II}^{20}}$. Décadas depois, o Conselho Ultramarino questionaria a procedência dessas armas. Em I745, após uma devassa tirada pelo Provedor da Fazenda da Paraíba sobre os descaminhos da Fazenda paraibana, o Conselho orientou que, pelos livros da Fazenda Real, o Provedor da Paraíba "examine que armas se repartiram ao povo por ordem do governador João da Maia da Gama, e de quem as recebeu ou cobrou a sua importância ou as repartiu sem arrecadação necessária"21.

Conforme apontou o governador, os conjurados, cientes de que apenas atingiriam seu intento caso o prendessem ou o assassinassem, começaram a planejar sua morte através de envenenamento ou tiro de espingarda, motivo pelo qual o governador passou a comprar espias e confidentes na capitania e nas suas vizinhas

$\mathrm{p}^{\mathrm{a}}$ que o avizassem de tudo, trazendo continuos correos por todas as partes pagos â sua custa, sustentando varias gentes, servindo se de Religiozos $\mathrm{p}^{\mathrm{a}}$ investigarem os animos, e tenções dos levantados, e lhe fazerem avizos; e o mesmo as espias e confidentes, no $q$ gastava $\mathrm{m}^{\text {to }}$ da sua fazenda, pois tudo era a custa della, excepto os Religiozos q elles fazião por zelo do Real serviço de VMag $^{\text {de22 }}$.

Enquanto isso, a nobreza pernambucana escrevia aos seus parentes e amigos da Paraíba $^{23}$ solicitando ajuda para debelar seus inimigos recifenses. O partido da nobreza pernambucana pretendia, através de seus aliados paraibanos, amotinar os soldados da capitania da Paraíba, cuja guarnição não recebia soldo nem farda havia um ano. Tomando

\footnotetext{
${ }^{19}$ Já em carta ao padre João da Costa, conforme visto anteriormente, João da Maia havia afirmado ter reunido 3 mil homens na capitania, inclusive muitos tapuias (GAMA, op. cit., p. 77).

${ }_{20}$ Requerimento (cópia) do capitão-mor da Paraíba, João da Maia da Gama, ao rei [D. João V] I7I2, AHU_ACL_CU_oI4, Cx. 4, D. 335.

${ }^{21}$ Carta do provedor da Fazenda Real da capitania da Paraíba 9/9/1745, DHBN, vol. C, p. 264-5.

${ }^{22}$ Requerimento (cópia) do capitão-mor da Paraíba, João da Maia da Gama, ao rei [D. João V] I7I2, AHU_ACL_CU_oI4, Cx. 4, D. 335.

${ }^{23}$ A relação de parentesco entre as elites pernambucana e paraibana era antiga, remontando ao próprio processo da conquista da capitania da Paraíba no século XVI. Gonçalves (2007), ao estudar esse processo, apontou a origem da elite local paraibana como sendo uma extensão da nobreza da terra de Itamaracá e, sobretudo, de Pernambuco, já que o núcleo inicial dos povoadores da Paraíba advinha, em grande parte, destas duas capitanias.
} 


\section{C) HițTó T́RICA}

conhecimento do plano, revelado por um padre que o soubera mediante confissão, João da Maia tratou de providenciar do seu bolso o pagamento e fardamento que se devia a infantaria, arrumando um empréstimo de $600 \$ 000$ réis, acalmando assim os ânimos da tropa $^{24}$ (SANTOS, op. cit., p. I2I; MELLO, op. cit., p. 394).

As cartas de João da Maia trocadas com o bispo D. Manuel e o Manifesto endereçado à nobreza não tinham surtido o efeito desejado, pois o sítio a Recife continuava. Contudo, se não podia socorrer pessoalmente o Recife, João da Maia tratou de impedir que concorresse gente ao cerco. Para a fronteira ao sul, o governador encaminhou forças lideradas pelo capitão-mor dos sertões Teodósio de Oliveira Ledo, com o objetivo de evitar a saída dos paraibanos devotos da facção da nobreza e impedir que eles enviassem recursos aos sitiantes. Para guardar a fronteira ao norte, João da Maia enviou o capitão-mor dos índios Luiz Soares a Mamanguape, no intuito de vigiar seus moradores - grande parte parenta da nobreza de Pernambuco -, revistar e prender quem fosse ou viesse do Rio Grande (MACHADO, op. cit., p. 367-8; MARIZ, I994, p. 48).

Conforme aponta Santos, a vigilância era tamanha que "não passava ninguem sem que primeiro fosse á prezença do dito governador, que o interrogava directamente, e por este modo alcançou muitas cartas da nobreza (que mandou a Sua Magestade), pelas quaes sabia tudo o que em Olinda se passava" (op. cit., p. 227). Ademais, os oficiais da Câmara paraibana, mesmo os devotos partidários da nobreza, também revelavam as cartas que recebiam de Olinda ao governador (Ibidem, p. I22). Nas palavras de Mello, "a atuação de João da Maia desencorajou os pró-homens da Paraíba, que passaram a cooperar, informando-o dos manejos dos parentes de Pernambuco" (op. cit., p. 395).

Devido às violências e arbitrariedades cometidas na execução dessas ordens por Luiz Soares, os moradores de Mamanguape levantaram-se contra ele, chegando a formar uma comissão para ir à cidade da Paraíba entregar ao governador uma petição solicitando sua substituição (SANTOS, op. cit., p. I2I; MACHADO, op. cit., p. 368).

Por três vezes tornaram com a mesma petição, sendo todas indeferidas. Na última tentativa, os três representantes dos interessados foram retidos na prisão subterrânea da fortaleza de Cabedelo pelo governador que, segundo Santos (op. cit., p. I22) "cheio de colera, metendo mão a uma faca, os investio chamando pelos da guarda, que os prendessem, e passassem corda a polée ${ }^{25}$, que os havia de polear”. Ainda de acordo com o autor, João da Maia

\footnotetext{
24 Requerimento (cópia) do capitão-mor da Paraíba, João da Maia da Gama, ao rei [D. João V] I7I2, AHU_ACL_CU_oI4, Cx. 4, D. 335.

${ }^{25}$ Instrumento de tortura usado na Inquisição, em Portugal do século XVI, consistia em uma roldana presa no teto, onde a vítima era suspensa, com pesos nos pés, deixando-a cair em brusco arranco sem tocar no chão.
} 


\section{C) GitcentórICA}

da Gama só não os torturou em virtude dos rogos dos religiosos que por eles intercederam. Todavia, os sujeitos permaneceram na prisão, onde o governador já havia metido "alguma gente plebéa" por se mostrar revoltosa.

De acordo com Pinto (I977, p. IO4-5), já em I7IO, João da Maia havia mandado o capitão Gonçalo Lopes de Oliveira com a sua companhia ao sertão, a fim de prender algumas pessoas que pretendiam ajudar a nobreza pernambucana. No mesmo ano, trincheiras diversas foram levantadas na capital no caminho para $\operatorname{Recife}^{26}$ e foram construídos um presídio no Cabo Branco $^{27}$ e a nova Casa da Pólvora ${ }^{28}$ - edificada em local estratégico, na encosta da ladeira de São Francisco, onde se pode ver toda a área do Porto do Varadouro com a foz do rio Sanhauá. Como sugere Barbosa (1994, p. 198), a conclusão da nova Casa da Pólvora em I710 demonstra a preocupação com a defesa da capitania e sua preparação para um possível ataque vizinho. Temor também apontado por Aguiar (1992, p. 295) e Coutinho e Ribeiro (200I, p. 470) ao mencionarem as trincheiras erguidas no caminho para Recife.

João da Maia, prevendo tumultos e hostilidades em decorrência do estado melindroso em que se encontrava a capitania, por motivo de segurança, mandou guardar toda a pólvora e artilharia existente no depósito da capital no forte de Cabedelo, onde possuía maior assistência, motivo pelo qual também nele se recolheu com uma guarnição de duzentos ou trezentos portugueses (SANTOS, op. cit., p. 227; MELLO, op. cit., p. 394-5).

O governador chegou a denunciar ao governador-geral do Brasil o plano dos moradores de Pernambuco pretenderem dominar a Paraíba, pedindo que o socorresse em segredo com dinheiro, munições e seiscentos homens. Inútil tentativa. D. Lourenço de Almada, subestimando sua acusação, rebateu que "nenhum caso fez das suas

\footnotetext{
${ }^{26}$ Próximo de onde atualmente se encontra a igreja Nossa Senhora de Lourdes - hoje, por esta razão, o local é chamado Rua das Trincheiras (AGUIAR, I992, p. 295; COUTINHO e RIBEIRO, 200I, p. 470).

${ }^{27}$ Cabo Branco, referido no período, não corresponde à atual praia de Cabo Branco, mas a toda zona litorânea que ia do atual Cabo Branco até Cabedelo, na barra do rio Paraíba (OLIVEIRA, 20I6, p. II2).

${ }^{28}$ Não sabemos quando a obra foi iniciada. Temos apenas registro de que, em I8 de janeiro de I709, encontravase em construção, pois o rei solicitou informação ao governador da Paraíba sobre o estado da obra na capital (PINTO, op. cit., p. IOO). A construção foi concluída em I7IO, conforme se pode verificar em uma inscrição ainda existente na fachada do monumento que diz: "Reinando em Portugal o $\mathrm{m}^{\circ}$ alto e poderoso Senhor Nosso D. João V e governando esta capitania João da Maia da Gama se fez este armazem. Anno de i7ıo". Antes de finalizada a construção, temos notícia que funcionavam três armazéns para guardar pólvora e armamentos. Os redutos possuíam estruturas precárias: paredes de grossura ordinária de pedra e barro, coberta de telha, sem abóbada ou forro algum, além de se localizarem no meio da povoação, o que as tornava suscetíveis a incêndios (Carta do capitão-mor da Paraíba, João da Maia da Gama, ao rei [D. João V] 2/6/17ı, AHU_ACL_CU_oI4, Cx. 4, D. 307; CONSULTA do Conselho Ultramarino, à infanta regente de Portugal, D. Catarina de Bragança II/8/1704, AHU_ACL_CU_OI4, Cx. 4, D. 268).
} 


\section{C) Histótórica}

representações", pelo conceito que sempre fez da nobreza da terra. Para ele, o pedido era apenas um embuste para conseguir recursos em favor dos mascates ${ }^{29}$.

João da Maia também preveniu seus vizinhos acerca da conspiração. Ao ser informado que, em junho de I7II, a nobreza pretendia pegar em armas para levantar as capitanias e apoderar-se das fortalezas, o governador precaveu o capitão-mor do Rio Grande, o sargento-mor do terço do Açu, o governador dos índios D. Sebastião Pinheiro Camarão e o mestre-de-campo dos pretos de Pernambuco Domingos Roiz Carneiro ${ }^{30}$.

A atitude de João da Maia foi essencial para impedir o socorro do Rio Grande à nobreza pernambucana. Embora o capitão-mor de Cunhaú tenha conseguido reunir tropa para acudir os parentes pernambucanos, não foi possível mobilizar os paulistas da guarnição do Açu. O governador dos índios do Rio Grande Antônio da Rocha Bezerra também fracassaria na sua tentativa de sublevar Natal e utilizar os índios das aldeias em favor de Olinda. Isso porque, por ordem dos capitães-mores da Paraíba, do Rio Grande, e de Luiz Soares, Antônio da Rocha foi assassinado na Paraíba, a caminho de Pernambuco (MELLO, op. cit., p. 395; GAMA, op. cit., p. 156).

André Nogueira, capitão-mor do Rio Grande, informou João da Maia que Antônio da Rocha Bezerra retirara de oito a dez barris de pólvora e alguns cunhetes de bala da fortaleza dos Reis Magos e conseguira reunir quatrocentos índios para marchar em favor da nobreza olindense, tendo, por conseguinte, de passar pelo território paraibano. Segundo Machado, após uma reunião na fortaleza de Cabedelo, João da Maia e Luiz Soares, assentaram a emboscada, a qual se efetivou às margens do rio Miriri. Assim, em decorrência do assassinato de seu comandante, a tropa retrocedeu (SANTOS, op. cit., p. 209; MACHADO, op. cit., p. 3967). Conforme aponta Santos, a morte de Antônio da Rocha foi muito lamentada pela nobreza pernambucana,

porque na chegada d'este homem com os indios e polvora tinhão estribadas todas as suas esperanças; e os Recifenses e defensores da praça estimarão-na, porque, si elle chegasse com a dita polvora e índios á Parahiba, onde o esperavão todos os inimigos do Recife, que, por não terem pés (como lá dizem) para poderem dar couces, estavão quietos, com a sua

\footnotetext{
${ }^{29}$ Carta que se escreveu aos oficiais do Senado da Câmara da cidade de Olinda 8/8/17II, DHBN, vol. XXXIX, p. 288; Carta que escreveu ao Capitão-mor da Paraíba, João da Maia da Gama 9/8/I7II, DHBN, vol. XXXIX, p. 29 I. ${ }^{30}$ Requerimento (cópia) do capitão-mor da Paraíba, João da Maia da Gama, ao rei [D. João V] I712, AHU_ACL_CU_OI4, Cx. 4, D. 335.
} 
chegada certissimamente se amotinava toda aquella capitania [Paraíba] contra o seo governador a favor da nobreza. (op. cit., p. 209)

As medidas de João da Maia da Gama também se estenderam a Goiana. Em meados de julho de I7II, uma revolta de aliados dos mascates eclodiu na vila, para onde João da Maia enviou 500 homens, sob comando de Luiz Soares ${ }^{31}$. As forças da Paraíba chegaram a declarar a anexação de Goiana a Paraíba, sendo nomeado Pedro de Mello, um dos adjuntos de Luiz Soares, o novo capitão-mor da vila. Os revoltosos desejavam levantar o cerco ao Recife (MACHADO, op. cit., p. 38I; GAMA, op. cit., p. 99). Sobre a ação, discorre Machado (op. cit., p. 382):

Era plano de João da Maia apoderar-se de Goyana, e ahi accumular todos os meios de resistência para ter seguro o caminho por onde pretendia surprehender pela retaguarda os sitiantes do Recife; e para poder ahi acharse livremente, sem admoestação da coroa, fez considerar aquelle territorio de sua jurisdição, o qual presidiou com a tropa de Luiz Soares.

No entanto, o movimento não vingou. Assim que a notícia chegou a Olinda, o governo deslocou contingentes para a região, a fim de restabelecer a ordem. Esmagando a manifestação em Goiana, a força expedicionária derrotou os homens de Luiz Soares, obrigando-os a regressarem para a Paraíba, sem alcançarem o propósito que almejavam (Idem; GAMA, op. cit., p. 99; MELLO, op. cit., 395).

Por volta de julho de I7II, João da Maia também escreveu cartas a alguns moradores da vila de Alagoas. Embora desconheçamos o teor do documento, certamente o envio se deu para cooptar apoio para os mascates na região ${ }^{32}$.

O governador-geral do Brasil D. Lourenço de Almada repeliu asperamente as atitudes do governador da Paraíba por oferecer auxílio de gente e mantimentos aos moradores de Recife, acusando-o de incitá-los e persuadi-los com promessas de socorrê-los em pessoa ${ }^{33}$. A intervenção de João da Maia levou a um flagrante choque de jurisdição com a autoridade. Ultrajado com a intromissão do governador da Paraíba em uma matéria que

\footnotetext{
${ }^{31}$ Em correspondência trocada com João da Mota, João da Maia já havia informado "da resolução em que estava de concitar o povo de Goiana contra o governo do bispo, e reunindo-se depois com as tropas da Parahyba atacar a linha de cerco pela retaguarda e acabar por uma vez com os enfados da nobreza da terra" (MACHADO, op. cit., p. 369).

${ }^{32}$ Carta que se escreveu ao Capitão-mor da vila das Alagoas 22/8/I7II, DHBN, vol. XXXIX, p. 293-4.

${ }_{33}$ Carta que escreveu ao Capitão-mor da Paraíba, João da Maia da Gama 9/8/I7II, DHBN, vol. XXXIX, p. 29 I-2.
} 


\section{C) GitistóñICA}

invadia sua competência, D. Lourenço advertiu João da Maia que sua jurisdição limitava-se ao termo da Paraíba, admoestação já antes formulada pela Câmara de Olinda. Nas irônicas palavras de D. Lourenço, João da Maia “esquecendo-se de que era Capitão-mor da Paraíba, se supôs Governador Geral do Estado do Brasil, querendo lhe usurpar cegamente a jurisdição"34.

Sem conseguir com sua argumentação convencer a nobreza a depor suas armas, nem encerrar o cerco ao Recife com auxílio militar prestado, pois falhara o golpe de Goiana, João da Maia permaneceu na fortaleza de Cabedelo, aguardando a vinda do novo governador de Pernambuco, já em viagem para a colônia (MACHADO, op. cit., p. 394-5). Após mais de três meses de sítio, no dia 6 de outubro de I7II, a frota anual finalmente chegaria trazendo Felix José Machado de Mendonça, o novo governador de Pernambuco, e o esperado desfecho do conflito.

\section{Grande, e inexplicável, e incrível serviço}

As providências tomadas por João da Maia durante a Guerra dos Mascates constituíram o ápice do seu serviço ao rei, segundo alegou o próprio governador. A seu ver, em 22 anos de serviços, tinha "por maior o que obrou nos levantes de Pernambuco" 35.

$\mathrm{Na}$ jactanciosa concepção do governador da Paraíba, devido à sua diligência e cuidado se evitou a total ruína de Pernambuco ${ }^{36}$. João da Maia reconhecia-se como responsável pela entrada, com a obediência devida, de Felix Machado em seu posto, momento em que se executaram as prisões, aplacando-se as alterações em Pernambuco. Sendo ainda mais enfático na sua participação, foi além e afirmou ser responsável pela manutenção da sujeição das capitanias do norte à autoridade do monarca português. Nas suas pretensiosas palavras, "a elle João da Maia da Gama, e não a outrem, deve principalm ${ }^{\text {te }}$ Vmagde o ter na sua Real obediencia todas estas Cap ${ }^{\text {nias }}$ desde o Rio de S. Francisco athe o Ciará e pode ser q o demais tambem" 37 .

Inegavelmente João da Maia realçou em demasia sua contribuição ao serviço régio ao reputar-se como principal responsável pela manutenção das conquistas desde o Rio São Francisco até o Ceará. No entanto, além do caráter presunçoso do governador, a própria

\footnotetext{
34 Carta que escreveu ao Capitão-mor da Paraíba, João da Maia da Gama 9/8/I7II, DHBN, vol. XXXIX, p. 29 I.

35 Consulta do Conselho Ultramarino, ao rei D. João V 3I/I/I715, AHU_ACL_CU_oI4, Cx. 5, D. 344.

36 Requerimento (cópia) do capitão-mor da Paraíba, João da Maia da Gama, ao rei [D. João V] I7ı2, AHU_ACL_CU_OI4, Cx. 4, D. 335.

37Idem.
} 


\section{C) HISTT́TórICA}

tipologia documental por ele utilizada demandava certa valorização dos seus feitos. Expliquemos. Nos documentos em que João da Maia expõe seus "grandiosos" serviços na guerra, ele requisitou uma série de mercês como remuneração de seus préstimos. Trata-se de requerimentos. Como se sabe, todo texto carrega em si uma intencionalidade. No caso dessa documentação oficial, isto é, um requerimento endereçado ao rei, o conteúdo político é muito expressivo, pois a motivação que leva o autor a escrever é ser agraciado com benesses. Pelos serviços prestados no conflito, João da Maia solicitou o governo de Pernambuco ou do Rio de Janeiro ou de Minas Gerais, 3 mil cruzados de soldo, uma ajuda de custo, uma comenda, e uma alcadaria- mor $^{38}$.

Ao escrever um requerimento solicitando uma mercê ao rei, era crucial ao solicitante investir na sua produção textual, isto é, munir-se de artifícios discursivos capazes de operar o convencimento através de argumentos e manobras retóricas. Trata-se do discurso peticionário, código de persuasão ávido de graças.

Pedro Cardim, em sua obra Cortes e Cultura Política no Portugal do Antigo Regime (I998), ao analisar as petições enviadas às cortes de Portugal seiscentista, discorre sobre as características do discurso peticionário: discurso típico, obediente a um determinado padrão formal, melhor dizendo, um código de enunciação. Nos documentos são encontradas manobras retóricas que visavam assegurar o êxito do pedido, ou seja, alguns artifícios discursivos pretendiam persuadir os oficiais reais quanto à legitimidade e relevância dos pleitos. Os solicitantes buscavam ter suas demandas reconhecidas como dignas, justificando assim o deferimento das graças.

Pontuar e exaltar os serviços prestados eram práticas extremamente correntes e necessárias entre os suplicantes, uma vez que compunham a lógica clientelar reinante na cultura política ${ }^{39}$ de Antigo Regime. A discussão em torno do conceito de cultura política tem atraído parte significativa da historiografia colonial. Estudiosos das sociedades do Antigo Regime têm considerado aspectos relativos a uma cultura política característica desta temporalidade como um todo, isto é, uma cultura política centrada "na dinâmica das sociedades de corte, na pessoa do rei enquanto cabeça capaz de articular o corpo social como um todo, na

\footnotetext{
${ }^{38}$ Requerimento (cópia) do capitão-mor da Paraíba, João da Maia da Gama, ao rei [D. João V] I7I2, AHU_ACL_CU_oI4, Cx. 4, D. 335; Consulta do Conselho Ultramarino, ao rei D. João V 31/1/1715, AHU_ACL_CU_OI4, Cx. 5, D. 344 .

39 Neste trabalho, servimo-nos da definição de cultura política delineada por Motta, segundo a qual o conceito de cultura política designa um "conjunto de valores, tradições, práticas, e representações políticas partilhado por determinado grupo humano, que expressa uma identidade coletiva e fornece leituras comuns do passado, assim como fornece inspiração para projetos políticos direcionados ao futuro" (MOTTA, 2009. cit., p. 2I).
} 


\section{C) HitșTórICA}

mistura entre o público e o privado, bem como uma indissociação entre o político, o econômico e o social" (GOUVÊA e SANTOS, 2007, p. 93).

Muitos estudiosos, ao tentarem entender a relação entre os indivíduos e, principalmente, entre os súditos e o rei nas sociedades de Antigo Regime, lançaram mão da noção de "economia moral do dom" de Marcel Mauss, na busca da compreensão do sistema de mercês na sociedade portuguesa e no seu vasto Império. Central na cultura política do Antigo Regime lusitano, a "economia moral do dom”, uma economia de favores e privilégios, era estruturada a partir de relações clientelares, onde predominavam critérios de fidelidade, amizade, parentesco, honra e serviço. A dinâmica política fundava-se em um círculo de interdependência. O imperativo régio de dar gerava uma cadeia de obrigações recíprocas. Lealdade e serviços prestados pelos súditos deveriam ser retribuídos por benesses régias, assim como a doação de mercês, por parte do rei, demandava gratidão e o serviço de seus vassalos (XAVIER e HESPANHA, I998).

Ao declararem-se indivíduos beneméritos, leais vassalos, os súditos tornavam-se credores de remuneração pela Coroa. A liberalidade real era fundamental como meio de cooptação de serviços, pois a concessão real de uma graça implicava na tácita imposição de receber algum serviço futuro.

Nesse sentido, orientava o Padre Antônio Vieira, em um trecho do Sermão da Visitação de Nossa Senhora no hospital da Misericórdia da Bahia em 2 de julho de I640, acerca da necessidade de El-Rey recompensar os serviços prestados pelos seus súditos: "Necessário é logo que haja prêmios para que haja soldados; e que nos prêmios se entre pela porta do merecimento; dêem-se ao sangue derramado, e não ao herdado somente; dêem-se ao valor e não à valia"40.

Essa lógica pautou a elaboração dos mencionados requerimentos redigidos por João da Maia. Ao solicitar as referidas mercês, o lusitano fez questão de ressaltar que o prêmio o animaria a sempre expor a vida no serviço de Sua Majestade ${ }^{41}$. Após exaltar todos os seus feitos, o governador argumentou:

Em concideração do referido, pede a $\mathrm{VMag}^{\mathrm{de}} \mathrm{q}$ inteirado, certificado e justificado do grande, e inexplicável, e increivel serviço q tem feito a VMagde (porq he $\mathrm{m}^{\text {to }}$ mais do $\mathrm{q}$ se podia esperar das suas posses, annos, e talento) se

${ }^{40}$ Cf. ALBUQUERQUE, 1968, p. II9-132.

${ }^{41}$ Consulta do Conselho Ultramarino, ao rei D. João V 31/I/I715, AHU_ACL_CU_oI4, Cx. 5, D. 344. 


\section{C) GitistóróRICA}

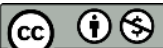

digne de mandar (...) premiar o seu merecim ${ }^{\text {to }}$ com premio, e satisfação não somte igual ao q merece, mas digna da Real grandeza de $\mathrm{VMg}^{\text {de }}$. $^{2}$

Anos antes, o governador já havia lembrado o monarca da necessidade de "premiar estes Ministros $\mathrm{p}^{\mathrm{a}} \mathrm{q}$ com o exemplo do premio se animem todos a se exporem a todos os perigos por servir a $\mathrm{VMg}^{\mathrm{de}} " 43$.

Como vimos, João da Maia buscou enaltecer sua participação na guerra, utilizandose da estratégia de engrandecimento dos serviços prestados. Entretanto, se é evidente que João da Maia exacerbou seu papel no processo, não é menos verdade que suas ações tiveram grande importância durante o conflito.

Quando da sublevação da nobreza, João da Maia afirmou que pretendia ir a Recife, a fim de intermediar a negociação entre os dois partidos, "tratando as couzas com o mediam ${ }^{\text {to }}$ entre elles"44. Não obstante tenha desistido de ir, enviou autoridades a Pernambuco para cumprir esse papel.

No decorrer do levante dos mascates, trocou vasta correspondência - lançando propostas conciliatórias - com os partidários da nobreza, escrevendo: à Câmara de Olinda, oferecendo-se para servir de mediador entre as duas facções; ao bispo D. Manuel, buscando persuadi-lo a usar seu poder de governador para evitar a "guerra injusta" contra os mascates; e à nobreza de Pernambuco, em um manifesto lançado com intuito de demovê-la do sítio ao Recife.

Se a tentativa de mediação fracassou, não podemos dizer o mesmo do amplo apoio logístico e militar oferecido por João da Maia aos mascates. Sua colaboração foi fundamental para a resistência mascate, uma vez que o governador enviou para Recife alguns barcos carregados de suprimentos, de modo a fortalecer a resistência dos recifenses por mais de três meses de cerco.

João da Maia também conseguiu inviabilizar a chegada de relevante reforço para a nobreza pernambucana, interceptando o socorro oriundo do Rio Grande. Pôs em armas a sua capitania, guardou suas fronteiras e efetuou prisões de familiares e pessoas coniventes com a nobreza pernambucana, de modo a sufocar implacavelmente qualquer repercussão na Paraíba.

\footnotetext{
${ }^{42}$ Requerimento (cópia) do capitão-mor da Paraíba, João da Maia da Gama, ao rei [D. João V] I712, AHU_ACL_CU_OI4, Cx. 4, D. 335.

${ }^{43}$ Carta do [capitão-mor da Paraíba], João da Maia da Gama, ao rei [D. João V] I6/12/1710, AHU_ACL_CU_oI4, Cx. 4, D. 324 .

${ }^{44}$ Idem.
} 


\section{C) Hitistór RICA}

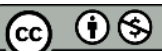

Além disso, correspondeu-se com as Câmaras de Itamaracá e Igarassu, requerendo que não se alterassem contra os moradores de Recife, e com alguns moradores da vila de Alagoas, no mesmo intuito. Já havia tentado, sem sucesso, marchar sobre Goiana. Daí a referência aos seus serviços "desde o Rio S. Francisco até o Ceará”, pois o raio de sua ação durante o levante extrapolou os limites da Paraíba, estendendo-se também a Pernambuco, Itamaracá e Rio Grande. Seu envolvimento foi tanto que o governador-geral D. Lourenço de Almada, como dito anteriormente, chegou a acusá-lo de cabeça da sublevação45.

No entanto, tal intervenção demandaria muitos gastos, consistindo no principal motivo alegado para seu endividamento durante a administração da Paraíba. Afinal, como lembrou João da Maia, sua participação foi efetivada "não só com as intelligencias da sua pessoa, mas com as despesas da sua própria fazenda" ${ }^{6}$. Em I7I2, o governador ressaltava sua penosa situação financeira. De acordo com suas enfáticas queixas, encontrava-se tão pobre e endividado, que não conseguiria se livrar nunca das dívidas, as quais já se acumulavam entre IO a I2 mil cruzados ${ }^{47}$.

O que teria, então, motivado João da Maia a realizar uma intervenção de tamanha expressão, incorrendo em sérios atritos com autoridades coloniais, com a nobreza pernambucana, além de vultuosos desembolsos, para apoiar os mascates?

Segundo apontam algumas fontes sobre a Guerra dos Mascates, João da Maia teria sido subornado. Fernandes Gama (op. cit., p. II4), em sua narrativa Memórias históricas da província de Pernambuco, indica que João da Maia da Gama foi comprado por I4 mil cruzados. Manoel dos Santos (op. cit., p. I66), em sua obra Narração histórica das calamidades de Pernambuco, sem especificar o montante, também afirma que o capitão-mor da Paraíba foi cooptado por dinheiro. Mello (op. cit., p. 37I), evocando tais fontes, corrobora que, em Goiana, o governador teria recebido suborno. Já para Boxer (op. cit., p. I42), não se deve crer nos pernambucanos quando sustentam que João da Maia havia sido subornado por I4 mil cruzados.

João da Maia, por motivos óbvios, jamais mencionou que recebera qualquer quantia dos mascates. Ao contrário, sempre fez questão de alardear que o desembolso feito naquela revolta era proveniente de seus próprios recursos, aumentando evidentemente seu mérito na iniciativa. Segundo destacou o governador em I7I2, com os dispêndios provocados para

\footnotetext{
${ }^{45}$ Carta que se escreveu aos oficiais do Senado da Câmara da cidade de Olinda 8/8/17II, DHBN, vol. XXXIX, p. 287; Carta para o Desembargador José de Arouche 9/8/17II, DHBN, vol. XXXIX, p.298.

${ }^{46}$ Consulta do Conselho Ultramarino, ao rei D. João V 31/I/1715, AHU_ACL_CU_OI4, Cx. 5, D. 344.

47 Requerimento (cópia) do capitão-mor da Paraíba, João da Maia da Gama, ao rei [D. João V] I712, AHU_ACL_CU_OI4, Cx. 4, D. 335.
} 


\section{C) HististórRICA}

mitigar o conflito "não só gastou tudo o q tinha, mas empenhou se tambem em Io ou I2 mil cruz $^{\text {os }}$, e vão continuando os empenhos por diante q continuão as alterações, e intento dos traidores" 48 .

No entanto, acreditamos ser possível e até mesmo provável que, de fato, João da Maia tenha auferido alguma contrapartida financeira dos mascates. Compartilhando o posicionamento de Mello (op. cit., p. 37I), consideramos, entretanto, que seria simplista atribuir unicamente ao pagamento a adesão ao movimento dos mascates. No caso de João da Maia, vimos que, desde o início do embate, quando do atentado contra Castro e Caldas, ele se prontificou a socorrer o governador pernambucano, alinhando-se de imediato ao partido dos mascates. Deste modo, qualquer valor porventura recebido, sem dúvida, deve ter animado-o a manter seu apoio ao grupo, mas não a definir sua posição no conflito.

A sedição da nobreza foi um movimento de repúdio à criação da vila do Recife. Descontentes com a ascensão política dos seus vizinhos, os olindenses tentaram barrar a todo custo a autonomia recifense. No entanto, ao se oporem à fundação da vila, a nobreza pernambucana estava contestando a determinação da Coroa, que estabelecia por um decreto régio a elevação de Recife à condição autônoma. Nesse sentido, o atentado contra Castro e Caldas constituía um ataque ao próprio poder régio, afinal, o governador constituía um representante dos desígnios do monarca nas conquistas.

Deste modo, nada mais esperado do que João da Maia, outro governador, sair prontamente em defesa de Castro e Caldas, sobretudo, quando um pedido de socorro de gente e mantimentos já havia sido expressamente dirigido ao governador paraibano. Segundo Mello, a solidariedade institucional entre os agentes régios sempre funcionaram a contento quando os interesses da Coroa eram postos em xeque pelos poderes locais. "Geralmente os agentes do monarca atuaram de concerto para limitar os poderes das Câmaras municipais e dos principais a terra" (Ibidem, p. 234).

Se a solidariedade era reinante entre quaisquer representantes do rei, que dizer entre cargos congêneres, como no caso de dois governadores. Nas palavras do próprio governador da Paraíba, socorrer Castro e Caldas era seu dever, "pellas obrigações de Ministro de VMgde e pella boa correspondência $\mathrm{q}$ tinha com elle estava prompto $\mathrm{p}^{\mathrm{a}}$ lhe hir assestir, $\mathrm{p}^{\mathrm{a}} \mathrm{o}$ hir deffender com todo o poder desta Cap ${ }^{\text {nia"49. }}$

\footnotetext{
${ }^{48}$ Idem.

${ }^{49}$ Carta do [capitão-mor da Paraíba], João da Maia da Gama, ao rei [D. João V] I6/12/1710, AHU_ACL_CU_OI4, Cx. 4, D. 324 .
} 


\title{
C) GitistóñICA
}

Ao mesmo tempo, pesava a proximidade entre as duas capitanias vizinhas. A intervenção de João da Maia na guerra também objetivava impedir o alastramento das alterações para a sua própria capitania. Nesse sentido, o tiro contra Castro e Caldas deve ter sido sentido na própria pele de João da Maia, que vislumbrava a possibilidade de seu cargo ser ameaçado por uma insurgência local.

Além disso, os caminhos trilhados pela nobreza pernambucana acabaram desembocando em ideias subversivas. Quando da fuga de Castro e Caldas para Bahia, o vácuo no poder desencadeou a especulação sobre novas e radicais formas de governo, inclusive, projetos secessionistas que desejavam romper com o jugo da metrópole e estabelecer um autogoverno ${ }^{50}$. Como lembra Mello, as aspirações independentistas "só poderiam ser satisfeitas mediante a violação da ordem legal e a instituição de um poder insurrecional" (Ibidem, p. 3II). Tais pretensões eram conhecidas por João da Maia. É o que vemos quando ele declarou:

\begin{abstract}
Se não me oppuzera por todos os caminhos, e meios aos traidores intentos dos ditos levantados, e parciaes seus, sem duvida algua arrazão a Villa, e Praça do $\mathrm{R}^{\mathrm{e}}$, passão tudo â espada, prezidião as fortallezas, fazem se senhores dellas, e vem levantar todas as capitanias, e faltão totalm ${ }^{\text {te }}$ a obediencia de VMagde, e põem em execução a sua premeditada Republica, q por tantas vezes intentarão."
\end{abstract}

João da Maia era um homem do rei, a quem não cabia compactuar com tais insurgências. Ao expor suas razões para intervir no levante em Pernambuco, repetidas vezes bradou sua lealdade ao serviço régio: "não obro por causa, nem por ninguem mais que por Deos, por El-Rei, e por conservação do Povo” (GAMA, op. cit., p. I07). Sendo ainda mais enfático, ressaltou: "não tenho carne, nem sangue, nem amigo, nem parente, nem cousa do mundo, que me obrigue a fazer o que faço, mais que o serviço de Deos, e d'El-Rei” (Ibidem, p. I09).

\footnotetext{
${ }^{50}$ Ao chegar em Pernambuco, o bispo D. Manoel se deparou com a resistência de alguns chefes da sedição à sua posse. Não havia consenso entre os líderes a respeito da entrega do governo ao prelado, nem de uma forma alternativa a adotar. Várias pretensões radicais emergiram diante do processo sucessório: escolha de um governador pernambucano; emancipação de Portugal; proclamação de um sistema republicano à moda de Veneza ou da Holanda; e a alternativa de um protetorado francês. Para conhecer melhor as ideias cogitadas, ver MELLO, op. cit., p. 303-330.

${ }^{5}$ Requerimento (cópia) do capitão-mor da Paraíba, João da Maia da Gama, ao rei [D. João V] I712, AHU_ACL_CU_OI4, Cx. 4, D. 335.
} 


\section{C) Gitistór RICA}

Contudo, isso não implica dizer que possíveis motivações e estratégias políticas não estivessem envolvidas na ação do governador. Paralelamente à lealdade ao rei, certamente coexistia o desejo de adquirir determinadas benesses régias, só passíveis de se serem conquistadas a partir de um considerável empenho no serviço régio.

Vale lembrar que se destacar como um leal vassalo durante as alterações em Pernambuco poderia ser um bom negócio para quem cobiçava galgar um posto mais alto na administração ultramarina, como era o caso de João da Maia. Respaldado nos serviços prestados durante a guerra, o governador ambicionou receber o governo de capitanias mais importantes - no que pese sua relevância econômica, política e simbólica - como Pernambuco, Rio de Janeiro e Minas Gerais. Além disso, como já vimos, a participação no conflito creditou o requerimento de outras benesses, como um soldo de 3 mil cruzados, uma ajuda de custo, uma comenda, e uma alcadaria-mor. Nada mais próprio ao universo político do Antigo Regime.

\section{Me pareceu mandar-vos agradecer}

A lealdade e a dedicação de João da Maia da Gama durante a Guerra dos Mascates acabaram sendo reconhecidas pelo monarca. A 8 de junho de I7II, o rei lhe endereçou uma carta tratando do seu procedimento durante a sublevação. Nesse momento, a atitude do governador seria louvada e, ao mesmo tempo, censurada pela Coroa. Não obstante o rei tenha agradecido pelo cuidado com que João da Maia procurou socorrer Sebastião de Castro e Caldas, advertiu que o governador não procedeu bem ao largar sua capitania52 (PINTO, op. cit., p. I05-6). Além de não ser lícito deixar o posto em que fora nomeado, sua ausência poderia incorrer em sérios prejuízos e perigos para as conquistas, expondo a capitania aos inimigos que "freqüentam tanto estes mares, que podiam facilmente tomar essa praça sem a menor resistencia se a fossem atacar" (Ibidem, p. I06). Afinal, o ultramar estava sob alerta, devido à ameaça francesa.

Dois anos mais tarde, João da Maia receberia novamente a gratidão do monarca pelo auxílio prestado na guerra em Pernambuco. Dessa vez, sem nenhuma incômoda reprimenda. Vejamos na íntegra o teor da carta régia:

${ }^{52}$ A repreensão referia-se ao fato de que, ao tomar conhecimento do tiro contra Castro e Caldas, João da Maia marchou, junto com o bispo D. Manuel, até Goiana. 


\section{C) GitistóróRICA}

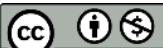

João da Maya da Gama. Eu El Rey vos envio muito saudar. Por ser informado do bem que vos houvestes na occasião em que os moradores de Olinda fizerão guerra aos do Recife. Me pareceo mandarvolo agradecer por esta. Escripta em Lix. ${ }^{a} 30$ de Março de I7I3. Rey. (Ibidem, p. IO7)

Outro indício, além dos agradecimentos expressos do monarca, que ratifica a aprovação da conduta de João da Maia pela Coroa é o longo período no qual ele governou a capitania da Paraíba: três triênios. Ademais, adiante temos a concessão do governo do Estado do Grão-Pará e Maranhão em I722, certamente em virtude dos seus serviços prestados na Paraíba. De fato, o posto não era o almejado por João da Maia, que já tinha solicitado o governo de outras capitanias de maior envergadura. No entanto, era comum que a mercê concedida fosse considerada pelo requerente inferior ao seu merecimento. Mesmo não sendo o cargo cobiçado, ainda assim, a nomeação mostra que João da Maia continuava um homem de confiança da Coroa.

Além do reconhecimento pela monarquia portuguesa, Marquês de Angeja, então governador-geral do Brasil, em outubro de I7I7, também respaldaria o desempenho de João da Maia, atestando a aprovação do seu governo, ao final da sua gestão. Ao comentar sobre o atraso na residência do governador, salientou que "pelo que toca a residência só se dilatariam as testemunhas em louvar a Vossa Mercê em jurarem os acertos e zelo com que governou e serviu a Sua Majestade nesse governo"53.

Tal imagem de João da Maia como um agente leal ao rei foi perpetuada na memória da capitania. Em I756, os oficiais da Câmara paraibana escreveram ao reino pronunciandose contra a anexação da capitania a Pernambuco. Eis que a Guerra dos Mascates seria relembrada. Buscando defender a manutenção da autonomia da Paraíba, os camarários destacaram a fidelidade dos vassalos paraibanos e a importância da sua isenção em relação a Pernambuco durante o conflito:

He certo que em todo o tempo forão os moradores desta capitania com grande utillidade publica leaes vassalos de V. Magestade, como mostramos nos dous levantes de Pernambuco quando tudo forão estragos, perturbaçoes, e dezordens, de que nos não nos livrariamos se fossemos sugeitos daquele governo, precizamente devíamos obedecer ás suas ordens $^{54}$.

\footnotetext{
53 Carta que se escreveu a João da Maia da Gama i3/Io/ı7I7, DHBN, vol. LXXXV, p. I5

54 Carta dos oficiais da Câmara da Paraíba, ao rei [D. José I], I9/5/1756, AHU_ACL_CU_OI4, Cx. I9, D. I495.
} 


\section{C) Hitsistórica}

Em seguida, são lembrados os feitos do capitão-mor da Paraíba:

Era governador da Parahiba João da Maia da Gama, que não só soube livrar deste incendio as terras da sua jurisdição apesar das deligencias dos enteressados, mas intentou aplacar as dezordens de Pernambuco, a cujo fim escreveo ao Bispo que governava as copias n. ${ }^{\circ}$ I e n. ${ }^{\circ} 2^{55}$, donde se ve qual era o seo zello, e quanto importante foi o ser independente para não se contaminar tão bem esta cappitania ${ }^{56}$.

Esta menção a João da Maia, quase cinquenta anos após o conflito, indica que a intervenção do ex-governador da Paraíba na guerra havia se consolidado na memória local como um honroso feito ao serviço de El-Rey. Sua fidelidade ao monarca, tantas vezes alardeada ao longo da guerra, era reconhecida pela posteridade paraibana.

\section{Considerações finais}

Longe de ser parte passiva na Guerra dos Mascates, João da Maia da Gama participou ativamente da trama, traçando planos e estratégias, protagonizando, inclusive, ousadas e ambiciosas ações. Procurando expandir sua jurisdição em competências e territórios que não lhe eram devidos, atritou-se com outros agentes régios, como o governador-geral D. Lourenço de Almada, por esbarrar em sua alçada de poder.

Nem sempre fiel às determinações da Coroa ou de seus oficiais e, por vezes, antecipando-se às suas ordens, ia "pondo o remédio que podia". Exceder-se no exercício de seu cargo, parece ter sido prática costumeira do governador João da Maia, como pudemos observar no conflito. Desobedecendo a certas determinações, ignorando outras, o governador inovava e acomodava obrigações que lhe eram delegadas.

Todavia, sua conduta no episódio não confrontou com seu papel de guardião dos desígnios régios nas conquistas. Embora tenha sido advertido de certos excessos, de um modo geral, prevaleceu a aprovação da Coroa a respeito de sua intervenção no conflito. Não obstante o monarca tenha estranhado que o governador abandonasse a capitania em um momento de grave ameaça externa, jamais questionou o seu amparo aos recifenses.

\footnotetext{
${ }^{55}$ Em anexo ao documento, os oficiais da Câmara remeteram as cartas de João da Maia da Gama enviadas a D. Manuel em I77I.

${ }^{56}$ Carta dos oficiais da Câmara da Paraíba, ao rei [D. José I], 19/5/I756, AHU_ACL_CU_ol4, Cx. I9, D. I495.
} 


\section{G) hitșTórica}

Imerso em um universo político onde a fidelidade à autoridade régia era a mais consagrada virtude para a constituição de um bom vassalo, João da Maia defendeu os intentos metropolitanos. Afinal, como não se pode deixar de considerar, nos governos do império português, em última instância, tudo era feito a serviço D’el-Rey.

\section{Referências:}

AGUIAR, Wellington Hermes Vasconcelos de. Cidade de João Pessoa: a memória do tempo. João Pessoa: Gráfica e Ed. Persona, 1992.

ALBUQUERQUE, Cleonir Xavier de. A remuneração de serviços da guerra holandesa (a propósito de um Sermão do Padre Vieira). Monografia n. 4. Recife: Imprensa Universitária, 1968.

BARBOSA, Cônego Florentino. Monumentos históricos e artísticos da Paraíba. 2 ed. João Pessoa: A União, 1994.

BOXER, Charles R. A idade de ouro do Brasil: dores de crescimento de uma sociedade colonial. 3 ed. Rio de Janeiro: Nova Fronteira, 2000.

CARDIM, Pedro. Cortes e cultura política no Portugal do Antigo Regime. Lisboa: Ed. Cosmos, 1998.

COUTINHO, Marcos Odilon Ribeiro e RIBEIRO, Natércia Suassuna Dutra. Logradouros da Grande João Pessoa. Personagens e fatos. João Pessoa: Sal da Terra, 200I.

GAMA, Fernandes José Bernardo. Memórias históricas da província de Pernambuco. Vol. IV. Recife: Arquivo Público Estadual, 1977.

GONÇALVES, Regina Célia. Guerras e açúcares: política e economia na Capitania da Parahyba, I585-I630. Bauru, SP: Edusc, 2007.

GOUVÊA, Maria de Fátima Silva e SANTOS, Marília Nogueira dos. Cultura política na dinâmica das redes imperiais portuguesas, séculos XVII e XVIII. In: ABREU, Martha; SOIHET, Rachel; GONTIJO, Rebeca (orgs.). Cultura Política e leituras do passado: historiografia e ensino de história. Rio de Janeiro: Civilização Brasileira, 2007, p. 89-110. MACHADO, Maximiano Lopes. História da Província da Paraíba. Vol. II. João Pessoa: Editora Universitária/UFPB, 1977 .

MARIZ, Celso. Apanhados históricos da Paraíba. $3^{\text {a }}$ edição. João Pessoa: A União, 1994. MARTINS, F. A. Oliveira. Um herói esquecido (João da Maia da Gama). Vol. I. Lisboa: Agência Geral das Colônias, 1944 . 


\section{C) Hitistór RICA}

MELLO, E. C. A fronda dos mazombos: nobres contra mascates. Pernambuco, I666-I715. São Paulo: Editora 34, 2003.

MOTTA, Rodrigo Pato (org.). Culturas políticas na história: novos estudos. Belo Horizonte: Argumentum/ FAPEMIG, 2009.

OLIVEIRA, Leandro Vilar. Guerras luso-holandesas na capitania da Paraíba (I63I-I634): um estudo documental e historiográfico. Dissertação (Mestrado em História). Centro de Ciências Humanas, Letras e Artes. Universidade Federal da Paraíba, 2016.

PINTO, Irineu Ferreira. Datas e notas para a história da Paraíba. Vol. I. João Pessoa: Editora Universitária/UFPB, 1977 .

PRADO JR., Caio. Formação do Brasil contemporâneo. São Paulo: Brasiliense/Publifolha. Coleção Grandes Nomes do Pensamento Brasileiro, 2000.

RICUPERO, Rodrigo. A formação da elite colonial: Brasil c.I530 - c.I630. São Paulo: Alameda, 2009.

SALGADO, Graça (coord.). Fiscais e meirinhos: a administração no Brasil colonial. Rio de Janeiro: Nova Fronteira, 1985.

SANTOS, Manuel dos Santos. Narração histórica das calamidades de Pernambuco. Revista do Instituto Histórico e Geográfico Brasileiro, tomo LIII, parte II. Rio de Janeiro: Imprensa Nacional, I890.

SOUZA, Laura de Mello e. O ouro da discórdia. Revista de História da Biblioteca Nacional, Rio de Janeiro, p. 54-56, I ${ }^{\circ}$ ago. 201 .

XAVIER, Ângela Barreto e HESPANHA, António Manuel. "As redes clientelares". In: HESPANHA, António Manuel (coord.). História de Portugal. O Antigo Regime (1620-1807), vol. 4. Lisboa: Editorial Estampa, 1998, p. 381-393.

Recebido em: 04 de outubro de 2020.

Aprovado em: 08 de dezembro de 2020. 